Tema: Aciaria Oxigênio

\title{
OTIMIZAÇÃO DO DESEMPENHO OPERACIONAL DA EDG- CSN ATRAVÉS DA APLICAÇÃO DE DESSULFURANTE MICRONIZADO A BASE DE CaO E ADITIVOS*
}

\author{
Claudio Marcio de Araujo ${ }^{1}$ \\ Eduardo Ribeiro ${ }^{2}$ \\ Ronaldo Carius da Cunha ${ }^{3}$ \\ Paulo César Pontelo ${ }^{4}$
}

\section{Resumo}

O trabalho apresenta o estudo e resultados da aplicação do dessulfurante micronizado Puresteel-1000, seus benefícios, economia e melhoria do processo de dessulfuração. Objetivando redução de custo e manutenção nos parâmetros operacionais a CSN desenvolveu junto a um fornecedor um dessulfurante a base de $\mathrm{CaO}$ que favoreceu o atendimento com redução de custo .A metodologia utilizada para o trabalho foi à avaliação do sistema produtivo da EDG-CSN, e o estudo de solução para o processo apoiado na revisão bibliográfica do tema. A implantação da aplicação do dessulfurante micronizado Puresteel-1000 obteve para a CSN ganho através da redução de custo de aproximadamente $30 \%$ no custo do dessulfurante, mantendo os mesmos parâmetros operacionais.

Palavras Chave: Dessulfuração; Ferro gusa; CaO; Carro torpedo.

\section{OPTIMIZATION OF OPERATING THE EDG-CSN THROUGH THE APPLICATION OF THE BASIS OF DESULFURIZING MICRONIZED CaO AND ADDITIVES}

\begin{abstract}
The paper presents the study and results from the application of micronized desulfurizing Puresteel-1000, its benefits, saving and improving the desulfurization process. Aiming at cost reduction and maintaining operating parameters CSN has developed along a one supplier desulfurizing the basis of $\mathrm{CaO}$ which favored the service at a reduced cost. Methodology used for the study was the assessment of the productive system the EDG-CSN, and the study solution for process supported in bibliographic review. The deployment of the application of micronized desulfurizing Puresteel-1000 got to CSN gain through cost reduction of approximately $30 \%$ in the cost of desulfurizing, maintaining the same operating parameters.
\end{abstract}

Keywords: Desulfurizing; Pig iron; CaO; Hot metal car.

1 Engenheiro, Coordenador de tratamento e transporte de gusa, CSN-GGAF, Volta Redonda, RJ, Brasil.

2 Engenheiro, Engenheiro de Produção, CSN-GGAF, Volta Redonda, RJ, Brasil.

3 Técnico Metalúrgico, Diretor, Sidertec, Sete Lagoas, MG, Brasil.

4 Engenheiro, Gerente Técnico, Departamento de Engenharia de Produto, Sidertec, Sete Lagoas, MG, Brasil.

* Contribuição técnica ao $45^{\circ}$ Seminário de Aciaria - Internacional, 25 a 28 de maio de 2014, 


\section{INTRODUÇÃO}

Com a busca incansável para alcançar índices cada vez mais altos em seus processos, as indústrias do setor siderúrgico vêm desenvolvendo processos cada vez mais criteriosos. A tendência mundial é gerar o produto final com qualidade superior, menor custo de fabricação que os demais concorrentes.

Buscando excelência no atendimento aos clientes, a Coordenação de Transporte e Dessulfuração de Gusa (CDG) realizou trabalho com para buscar melhores resultados, no processo de dessulfuração de gusa em carros torpedo, na redução do custo de dessulfuração e para isto, desenvolveu uma nova mistura de agente dessulfurante para ser utilizado em substituição ao agente dessulfurante utilizado à base de $\mathrm{CaC}_{2}$, e também o desenvolvimento de um novo fornecedor, visto que à mais de 10 anos a CSN trabalha apenas com 01 fornecedor de agente dessulfurante.

Sendo assim, foi realizado um estudo para inicialmente buscar empresas com capacidade para desenvolver, produzir e atender a demanda da CSN, garantindo o atendimento ao cliente aciaria, com qualidade e baixo custo.

Conforme a Figura 1 verifica se que apesar das médias anuais não se alterarem, ocorre uma variação de pontos de enxofre que são percebidas nos meses de janeiro a setembro de 2013.

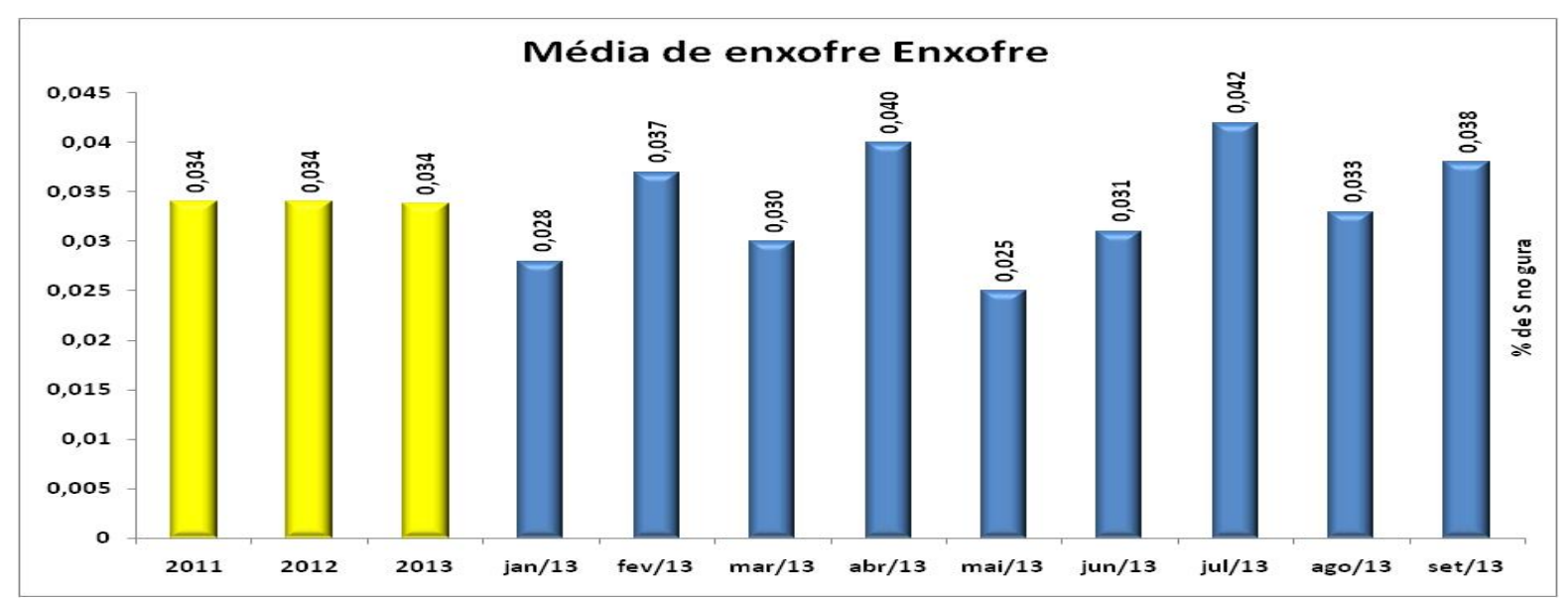

Figura 1. Média do enxofre produzido nos Altos Fornos.

Conforme a Figura 2, verifica se que o desvio padrão do enxofre dos altos fornos tem se elevado, o que eleva o consumo de agente dessulfurante devido à necessidade de injeções de maiores quantidades de agente dessulfurante, no qual não se tem ação pela necessidade de atendimento ao cliente aciaria com enxofre no final de dessulfuração que varia de $0,012 \%$ a $0,015 \%$ ou menor em caso de uma necessidade especial.

* Contribuição técnica ao $45^{\circ}$ Seminário de Aciaria - Internacional, 25 a 28 de maio de 2014, 

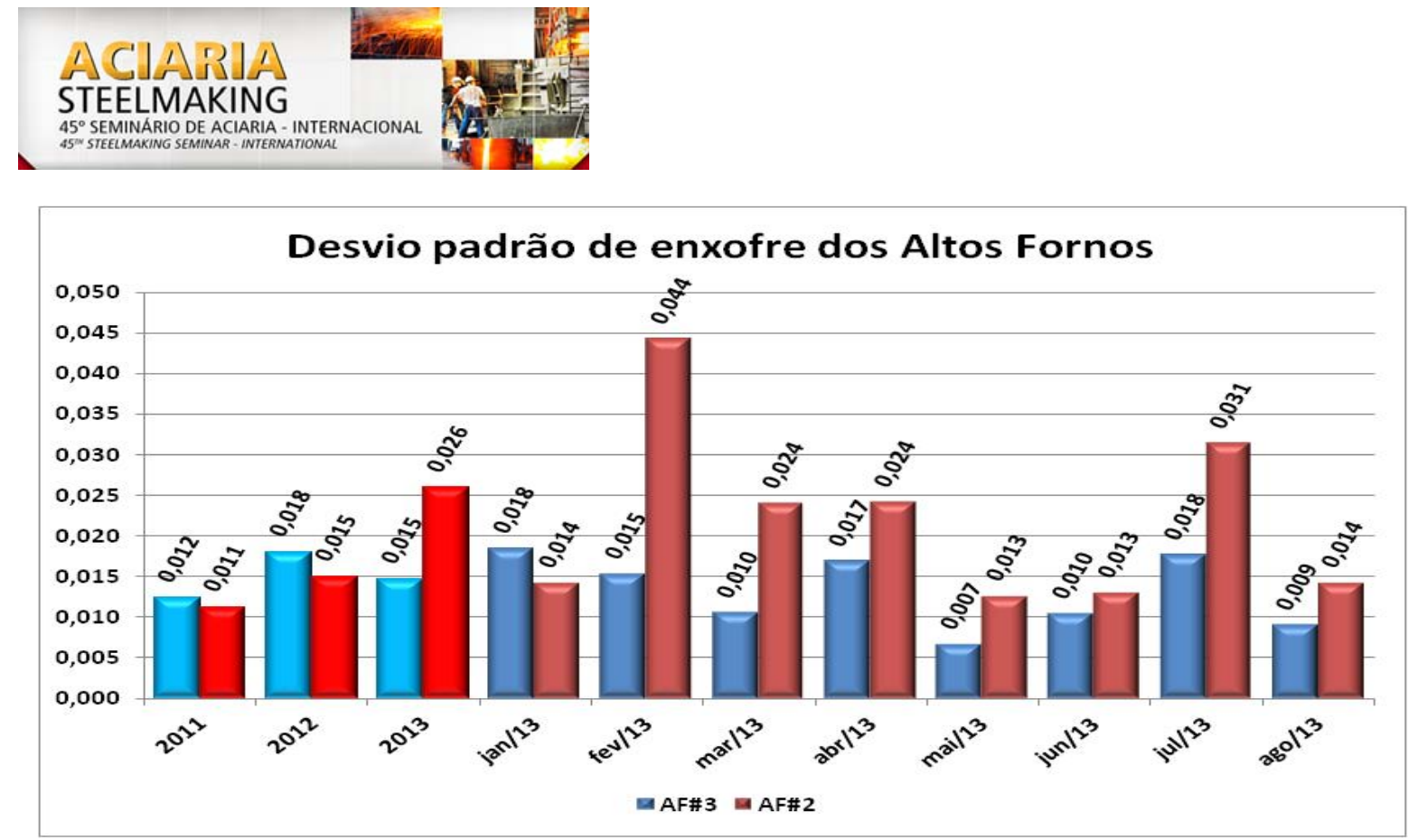

Figura 2. Desvio Padrão do enxofre dos Altos Fornos.

\section{MATERIAIS E MÉTODOS}

A dessulfuração do ferro-gusa é feita, principalmente, através do CaO de acordo com as equações abaixo.

A Equação 1 ocorre quando o oxigênio liberado pelo $\mathrm{CaO}$ reage com o carbono presente no gusa, e a Equação 2, quando esse oxigênio reage com alumínio, que pode ser adicionado em uma mistura dessulfurante conforme Turkdogan [1].

$$
\begin{gathered}
\mathrm{CaO}(\mathrm{s})+\underline{\mathrm{S}}+\underline{\mathrm{C}}=\mathrm{CaS}(\mathrm{s})+\mathrm{CO}(\mathrm{g}) \\
3 \mathrm{CaO}(\mathrm{s})+3 \underline{\mathrm{S}}+\mathrm{Al}(\mathrm{s})=\left(\mathrm{Al}_{2} \mathrm{O}_{3}\right)+(\mathrm{CaS})
\end{gathered}
$$

A premissa principal para o processo de dessulfuração do ferro-gusa é a de criar condições para a formação do sulfeto; sendo que quanto mais baixo o teor de oxigênio contido no ferro-gusa, mais eficiente é o processo, por isso as misturas dessulfurantes, geralmente, são constituídas do agente dessulfurante, um desoxidante, normalmente o alumínio, e um fundente de acordo com Campos [2].

Do ponto de vista operacional, a CSN trabalha hoje com uma estação de dessulfuração de gusa em carro torpedo composta por 04 boxes de dessulfuração por onde passa todo o ferro gusa produzido pela usina, sendo que neste ponto o ferro gusa é dessulfurado até $0,012 \%$ de enxofre conforme necessidade da aciaria.

A usina trabalha com a aplicação de um agente dessulfurante a base de carbureto de cálcio que tem elevado custo e possui ainda riscos operacionais inerentes as características do produto de inflamabilidade e explosividade o que pode gerar riscos potenciais a operação sendo, portanto segurança também alvo deste trabalho. Assim sendo para configuração do trabalho serão usadas ferramentas da qualidade a fim de facilitar a avaliação do sistema produtivo atual.

Segundo Miguel [3] as ferramentas da Qualidade são usadas como suporte ou apoio à decisão na análise de determinado problema.

As Sete Ferramentas mais conhecidas da Qualidade, de acordo com Miguel [1], são: diagrama de causa-efeito, histograma, gráfico de pareto, diagrama de correlação, gráfico de controle e folha de verificação. A partir desta analise então o trabalho irá utilizar da ferramenta mais adequada para este fim, o diagrama de causa-efeito.

* Contribuição técnica ao 45 Seminário de Aciaria - Internacional, 25 a 28 de maio de 2014, 
Esta ferramenta consiste em uma forma gráfica usada como metodologia de análise para representar fatores de influência sobre um determinado problema. O diagrama de causa-efeito pode ser realizado focado nas etapas abaixo:

- Determinar o problema a ser estudado;

- Verificar sobre as possíveis causas e registrá-las no diagrama;

- Construir o diagrama agrupando as causas em "6M"

- Analisar o diagrama, a fim de identificar as causas verdadeiras;

- Corrigir o problema.

Assim sendo, com base nos dados levantados, foi elaborado o Diagrama de ISHIKAWA representado na Figura 3, onde é possível verificar as possíveis causas do "Elevado custo de dessulfuração de carros torpedo".

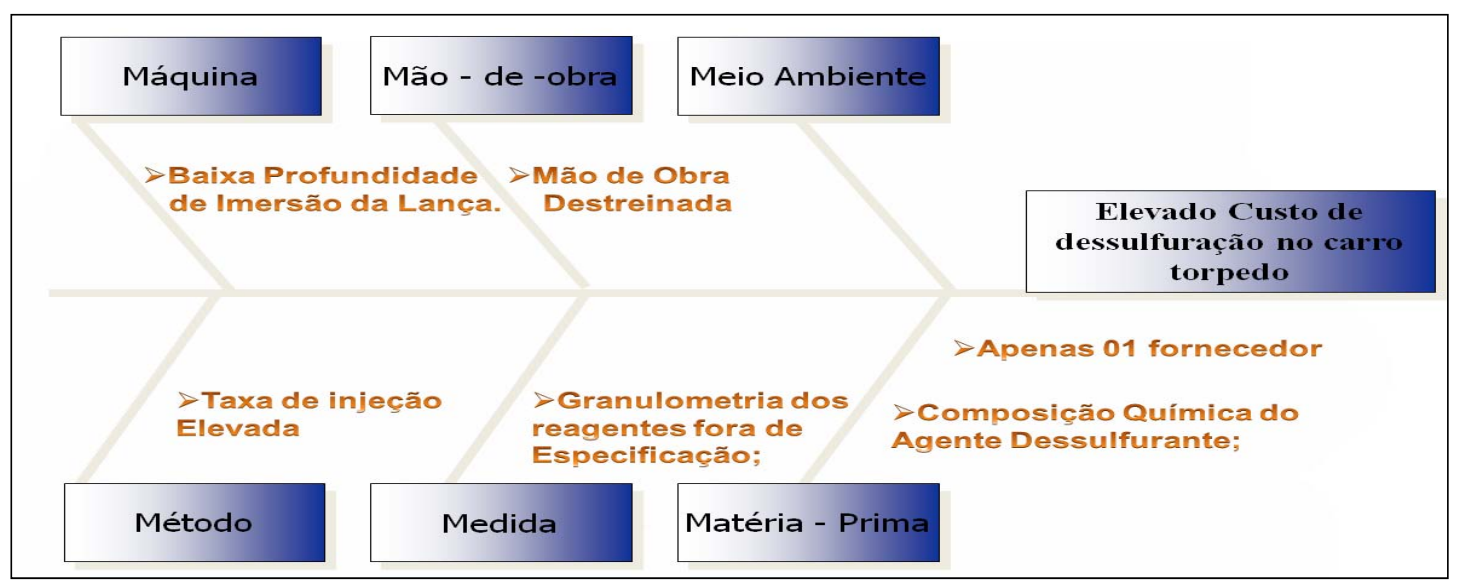

Figura 3. Diagrama de ISHIKAWA.

Depois de levantadas as informações para construção do diagrama de Ishikawa foram efetuadas analises sobre as causas levantadas conforme a Tabela 1 onde são descritas suas análises.

Tabela 1. Análise das causas

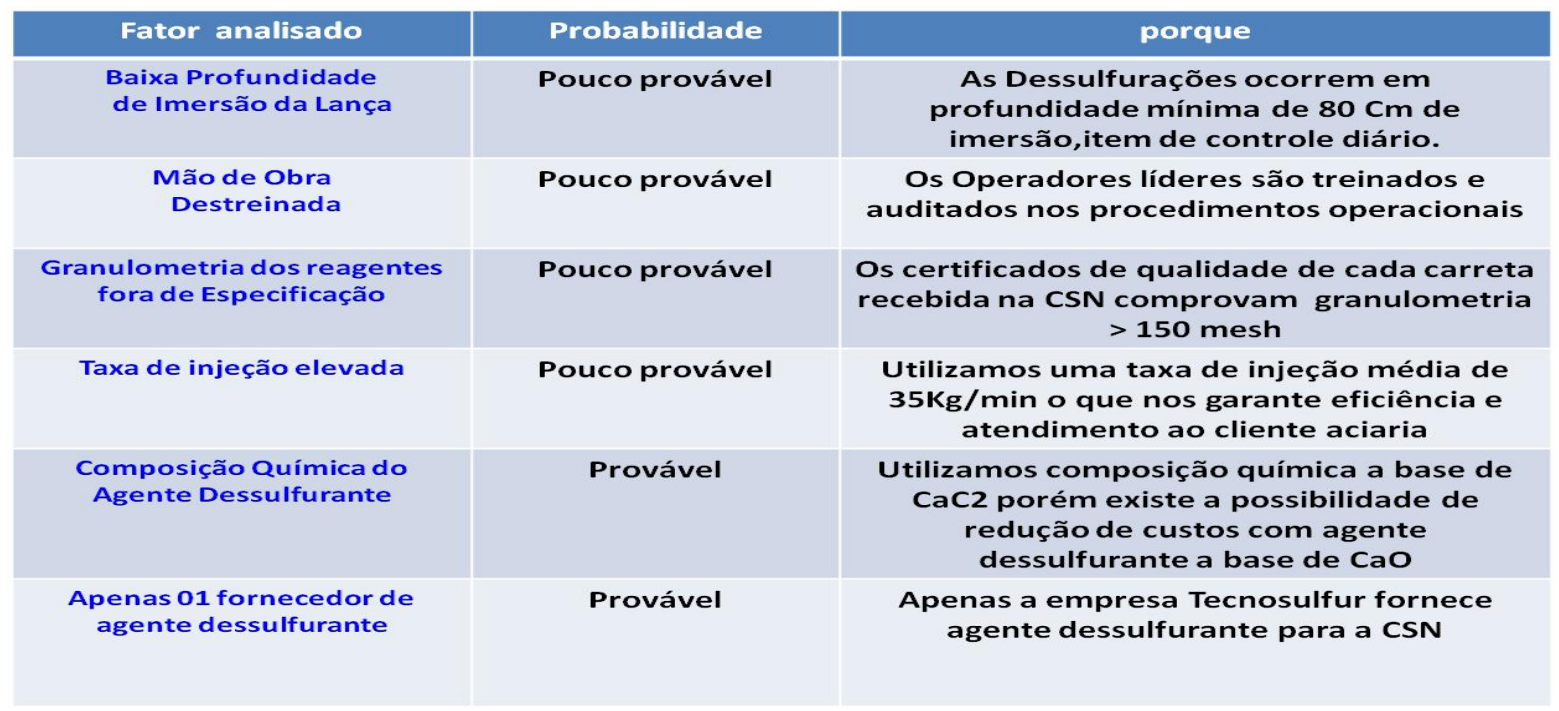

Com os problemas identificados, percebe-se que a solução a ser adotada seria a modificação da composição química do agente dessulfurante, utilizando uma mistura

* Contribuição técnica ao $45^{\circ}$ Seminário de Aciaria - Internacional, 25 a 28 de maio de 2014, Porto Alegre, RS, Brasil. 
a base de $\mathrm{CaO}$ de custo mais baixo que a utilizada atualmente,contendo o $\mathrm{CaC}_{2}$ que eleva o custo do agente dessulfurante.

Foi identificada também a necessidade de desenvolvimento de novo fornecedor, visto que na CSN só há um fornecedor de agente dessulfurante, gerando dificuldades do departamento comercial em negociar melhores preços. Desta forma foram definidas as ações conforme Quadro 1.

Quadro 1. Ações para implantação da proposta

\begin{tabular}{|c|c|c|c|c|}
\hline Item & O Que & Responsável & Prazo & Situação \\
\hline 1 & Desenvolvimento de novo fornecedor & $\begin{array}{c}\text { Claudio } \\
\text { CDG }\end{array}$ & $15 / 02 / 2012$ & OK \\
\hline 2 & Cadastrar no CADMAT o código para testes & $\begin{array}{c}\text { Celso } \\
\text { CDG }\end{array}$ & $15 / 06 / 2012$ & Ok \\
\hline 3 & Testar material e avaliar performance & $\begin{array}{c}\text { Átila } \\
\text { CDG }\end{array}$ & $30 / 11 / 2012$ & OK \\
\hline 4 & $\begin{array}{c}\text { Realizar a compra dos dessulfurantes após } \\
\text { testese aprovação }\end{array}$ & Juliana DSUL & $30 / 09 / 2012$ & Ok \\
\hline 5 & $\begin{array}{c}\text { Definir parâmetros para trabalho com } \\
\text { utilização de CaO sem silo dedicado }\end{array}$ & Eduardo CDG & $15 / 04 / 2013$ & Ok \\
\hline
\end{tabular}

Dando andamento ao processo de desenvolvimento, foi feita então pesquisa de mercado em dezembro de 2011 nas principais siderúrgicas do Brasil para conhecer os tipos de dessulfuração e os fornecedores de agente dessulfurante das mesmas, no qual foram constatados que os fornecedores de agente dessulfurante disponíveis no mercado eram a Stolberg, Sidertec, Tecnosulfur, Vamtec e RIMA, e que parte das siderúrgicas utilizavam $\mathrm{CaO}$ de produção própria.

O próximo passo foi realizar avaliação das empresas fornecedoras com potencial para fornecimento de agente dessulfurante para a CSN, sendo então avaliados quatro fornecedores quanto a custo, capacidade produtiva, logística, e histórico de fornecimento.

Após avaliação foi decidido optar pela Sidertec devido as suas características conforme abaixo.

\subsection{Análises}

- Capacidade de atendimento de $100 \%$ da demanda da CSN se necessário;

- 18.000 toneladas/mês 600 toneladas/dia;

- Baixo custo do produto;

- Profissionais com conhecimento do processo de dessulfuração da CSN e mais de 10 anos de experiência em processos de dessulfuração;

- Localização da fábrica em Sete Lagoas não altera o custo de transporte.

Entre os itens avaliados, um dos mais importantes foi o fator logístico, levando em consideração que a fornecedora atual e a concorrente estão na mesma região, desta forma não alterando nossa característica de custo logístico.

Foi concluído, portanto que pelos motivos acima citados o fornecedor que possibilitaria atingir a meta de redução de custo de dessulfuração e desenvolvimento de novo fornecedor seria a empresa Sidertec.

A partir da escolha do fornecedor, iniciou se o desenvolvimento do novo agente dessulfurante.

* Contribuição técnica ao $45^{\circ}$ Seminário de Aciaria - Internacional, 25 a 28 de maio de 2014, 


\section{$A C I A R I A$}

Neste momento foi contatado o fornecedor e desenvolvida composição de material a base de $\mathrm{CaO}$ voltado para atendimento a CSN, sendo então preparados testes de aplicação do produto para confirmação de performance.

A composição química da composição está entre os seguintes parâmetros:

$75 \% \quad \mathrm{CaO}$

$15 \% \quad \mathrm{CaCO}_{3}$

$7 \% \quad \mathrm{Al}$ (Met)

$1 \% \quad \mathrm{CaF}_{2}$

$2 \%$ Polímeros

Para que os testes ocorressem com sucesso, sem o risco de perda de produção do cliente aciaria por falta de gusa ou carros torpedo com enxofre fora da especificação, foram adotados procedimentos:

- Carregamento de carreta com 01 silo com 17 toneladas e mais 01 silo com 32 toneladas do agente dessulfurante de teste;

- Esvaziamento do silo principal da EDG;

- Abastecimento do silo principal da EDG com o material de teste;

- Avaliação de desempenho e resultados metalúrgicos do material;

- Estoque de segurança de agente dessulfurante a base de $\mathrm{CaC}_{2}$.

\section{RESULTADOS}

Após a aplicação inicial conforme Figura 4 com a aplicação da nova mistura a base de $\mathrm{CaO}$ inicialmente em 12 Carros Torpedo, percebeu se que os resultados metalúrgicos de enxofre objetivado foram atingidos, garantindo a qualidade e atendimento ao cliente aciaria sem a necessidade de injeção de material extra garantindo também o mesmo tempo de dessulfuração não afetando a entrega.

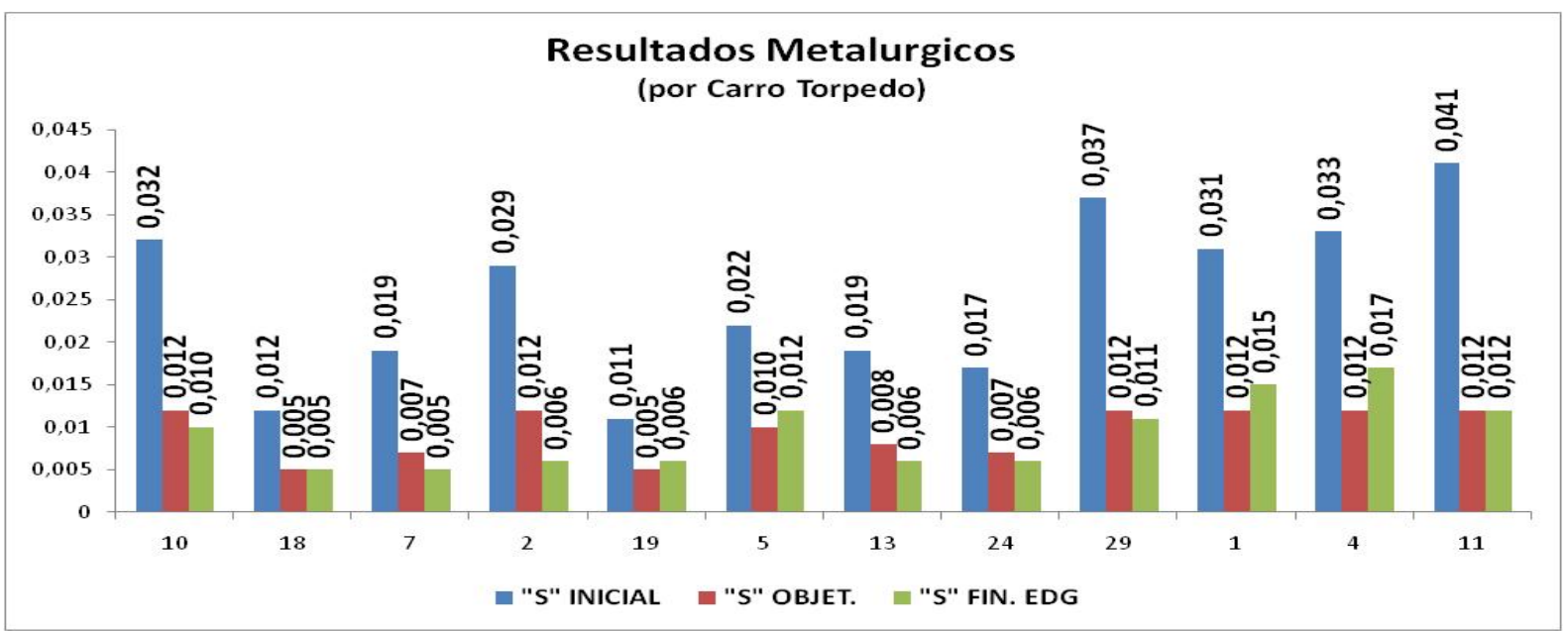

Figura 4. Resultados metalúrgicos da $1^{a}$ aplicação.

Foi identificada elevação de temperatura nos sistemas coletores de pó, com temperaturas superiores a $110^{\circ} \mathrm{C}$, e seguidas aberturas do sistema de ar frio do sistema, com risco de queima dos elementos filtrantes e de parada da planta, devido a este fato foram devolvidas 32 toneladas das 49 toneladas recebidas para ajustes da mistura para novos testes.

Assim sendo foi realizada correção da composição e realizada nova aplicação conforme Figura 5, sendo percebido que com a aplicação da mistura modificada a base de $\mathrm{CaO}$ na quantidade de 25 toneladas, os resultados metalúrgicos de enxofre

* Contribuição técnica ao $45^{\circ}$ Seminário de Aciaria - Internacional, 25 a 28 de maio de 2014, Porto Alegre, RS, Brasil. 
objetivado foram atingidos, e os níveis de temperatura dos coletores de pó se mantiveram normais.

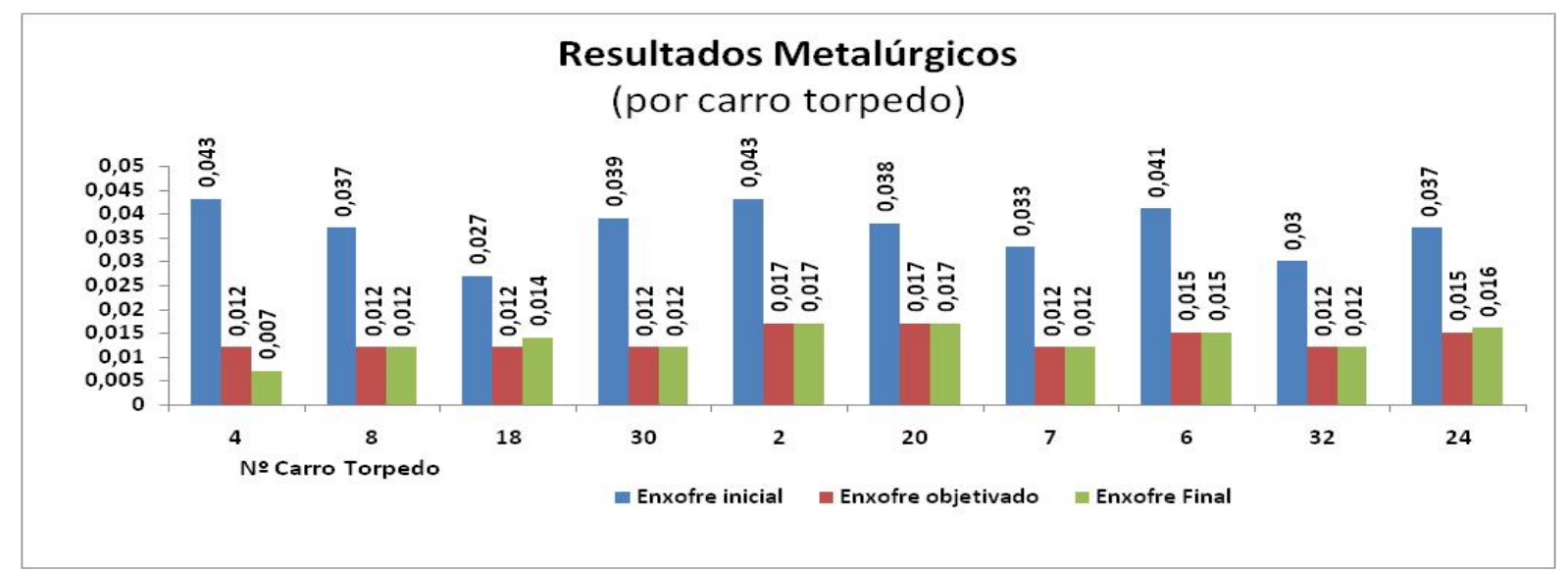

Figura 5. Resultados metalúrgicos da $2^{\mathrm{a}}$ aplicação.

Após a $2^{\mathrm{a}}$ aplicação o material foi aprovado para realização de testes maiores a fim de evidenciar estatisticamente os resultados que conforme verificado na Figura 7, nas médias das aplicações que ocorreram dos dias 25 a 31/10/2012 os resultados metalúrgicos de enxofre objetivado foram atingidos, garantindo a qualidade e atendimento ao cliente aciaria sem a necessidade de injeção de material extra garantindo também o mesmo tempo de dessulfuração não afetando a entrega como nas aplicações anteriores.

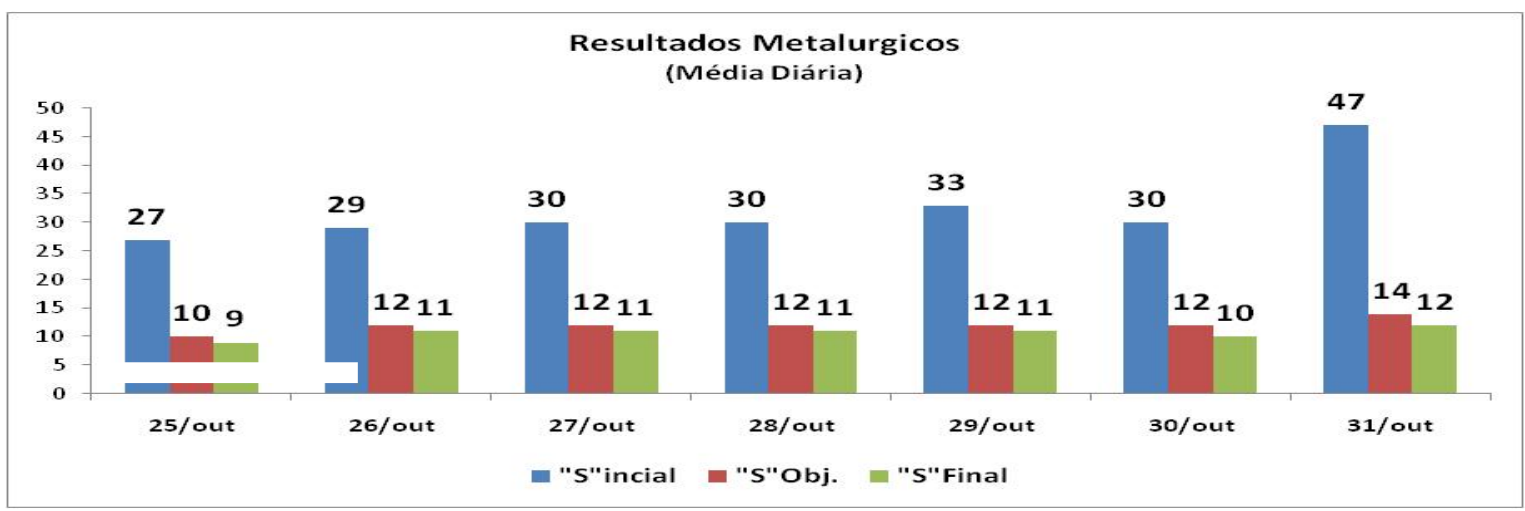

Figura 6. Resultados metalúrgicos da $3^{a}$ aplicação.

Foi identificada em toda a aplicação a elevação de temperatura nos sistemas coletores de pó, com temperaturas superiores a $110^{\circ} \mathrm{C}$, e elevação da tara dos carros torpedo conforme a Figura 7, o que diminui a capacidade de transporte de gusa dos mesmos, também houveram ocorrências de obstrução do sistema de transporte de pó do sistema de despoeiramento, devido a estes efeitos foram solicitadas novas modificações na composição química da mistura para que continuássemos a análise de performance.

* Contribuição técnica ao $45^{\circ}$ Seminário de Aciaria - Internacional, 25 a 28 de maio de 2014, 

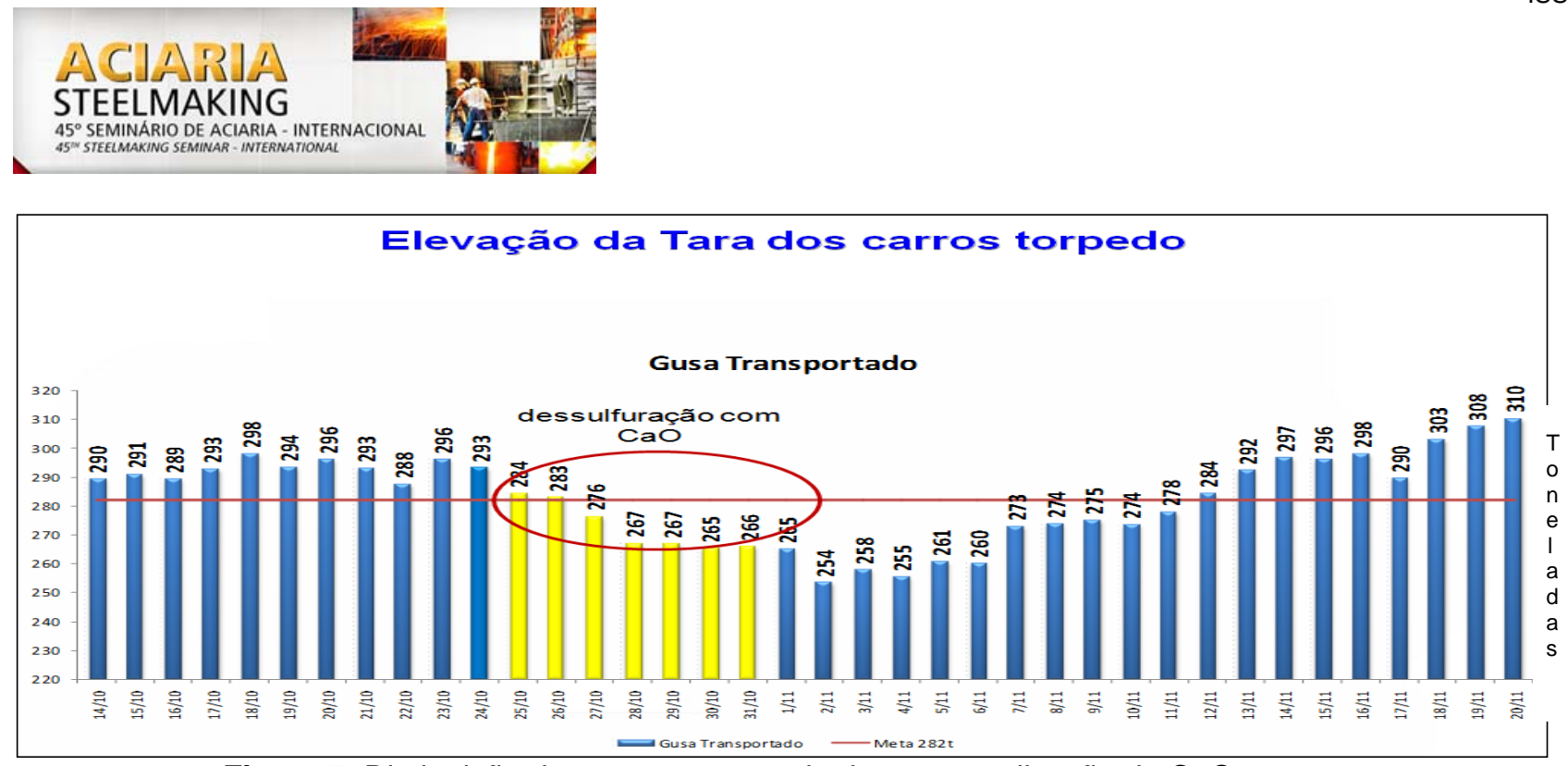

Figura 7. Diminuição do gusa transportado durante a aplicação de CaO.

Após aplicações mensais foi possível observar que as modificações na mistura base de $\mathrm{CaO}$ surtiram efeitos, e conseguiu se amenizar e controlar os efeitos indesejáveis das altas temperaturas, foi continuado o trabalho com ocorrências de temperatura elevada nos coletores porém em níveis controlados, eventualmente pode ocorrer queda da capacidade de transporte de gusa de carros torpedo conforme a Figura 8; porém a mesma não coloca em risco a segurança operacional dos Altos Fornos e dessulfuração de gusa.

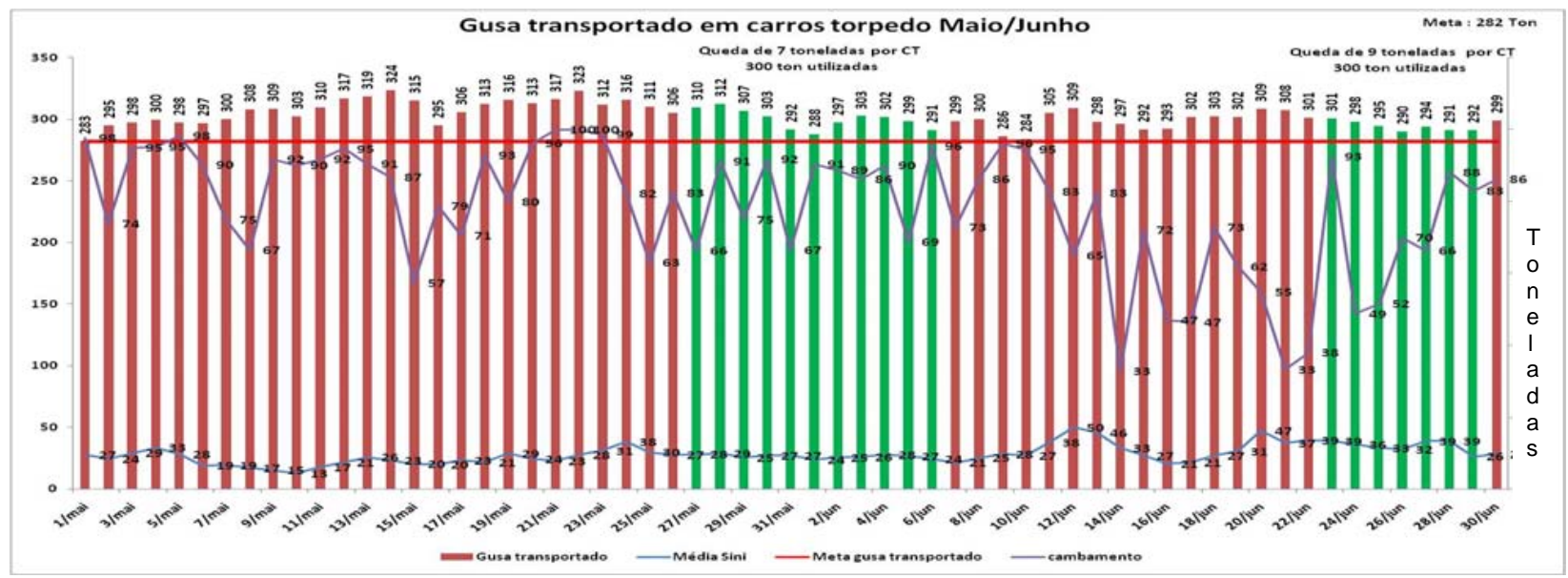

Figura 8. Manutenção do gusa transportado durante a aplicação de CaO - Mai/Jun-2013.

\section{DISCUSSÃO}

Avaliando a qualidade do metal após tratamento percebe-se por analises químicas que não houve modificação da qualidade do gusa entregue ao cliente aciaria.

Quanto às avaliações de meio ambiente, houve pequena elevação da geração de escória, porém a mesma foi suportada pelo processo sem a necessidade de investimento para destinação da mesma.

Diferente do agente dessulfurante à base de $\mathrm{CaC}_{2}$ que em contato com a água gera o gás acetileno, e entra em combustão sem necessidade de ignição; o agente dessulfurante à base de $\mathrm{CaO}$ não é inflamável. O que torna a sua aplicação segura assim garantindo uma aplicação com menores riscos operacionais no que tange a segurança elevando assim a confiança do pessoal a segurança do patrimônio sempre lembrando de que já existiram acidentes até mesmo fatais com a utilização de carbureto de cálcio.

* Contribuição técnica ao 450 Seminário de Aciaria - Internacional, 25 a 28 de maio de 2014, Porto Alegre, RS, Brasil. 


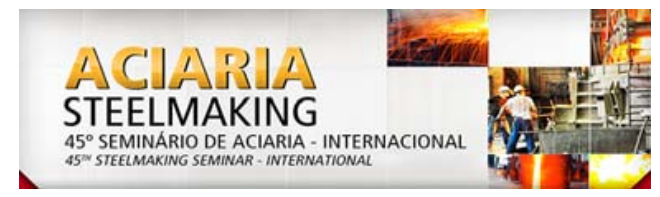

A segurança operacional do material permite ainda operações seguras de manutenção evitando assim a exposição dos colaboradores a riscos, a facilidade na programação de intervenções levando em consideração que não é necessária completa limpeza da linha para execução de serviços de corte e solda.

Sobre e eficiência, a aplicação do agente dessulfurante a base de CaO ocorre em quantidades iguais a do agente dessulfurante a base de $\mathrm{CaC}_{2}$, o que garante 0 mesmo tempo de dessulfuração.

Houve redução do custo do agente dessulfurante devido ao agente dessulfurante a base de $\mathrm{CaO}$ ter o custo $30 \%$ menor que o agente dessulfurante utilizado a base de CaC2 o que possibilitou uma economia real que favoreceu a competitividade da usina no cenário siderúrgico nacional.

\section{CONCLUSÃO}

Com a busca de novas tecnologias e novas parcerias no mercado, o Trabalho atingiu o Objetivo de Redução do Custo do Agente Dessulfurante, conseguiu se também o desenvolvimento de novo fornecedor, o que possibilitou ao departamento comercial de CSN negociar preços de agente dessulfurantes o que era difícil pelo fato de não haver concorrência, também se obteve ainda uma redução de custo de $30 \%$ no custo de dessulfuração.

\section{REFERÊNCIAS}

1 Turkdogan ET. Fundamentals of Steelmaking. London: The Institute of Materials; 1996. Cap 9, p.245-292.

2 Campos VF. Tecnologia de fabricação do aço líquido. $3^{a}$ ed. Belo Horizonte: UFMG; 1985. Cap.7, p.64-184.

3 Miguel PAC. Qualidade: enfoques e ferramentas. $1^{\text {a }}$ ed. São Paulo: Artliber; 2006. Cap.6, p.225-226.

* Contribuição técnica ao $45^{\circ}$ Seminário de Aciaria - Internacional, 25 a 28 de maio de 2014, 